\title{
LA NARRATIVA COMO MODALIDAD BÁSICA DE COGNICIÓN. APORTES NARRATOLÓGICOS A LA CIENCIA PSICOLÓGICA
}

\author{
NARRATIVE AS A BASIC MODALITY OF COGNITION. NARRATOLOGICAL \\ CONTRIBUTIONS TO PSYCHOLOGICAL SCIENCE
}

\author{
Dante Duero* \\ Universidad Nacional de Córdoba (Secyt), \\ Córdoba - Argentina. \\ Recibido enero de 2019/Received January, 2019 \\ Aceptado agosto de 2019/Accepted August, 2019
}

\begin{abstract}
RESUMEN
En este trabajo nos hemos propuesto discutir y analizar la propuesta del filósofo Walter Burkert, a la luz de las consideraciones hechas por diferentes narratólogos respecto del rol de la narrativa como habilidad cognitiva. Para Burkert, el surgimiento y la supervivencia de ciertos artefactos culturales, como los mitos y los cuentos tradicionales puede explicarse por la efectividad y eficiencia que los mismos expresan en tanto herramientas para almacenar y transmitir información relevante para la especie. Entre las virtudes y potencialidades que tienen los cuentos y las historias simples podemos remarcar que son fáciles de recordar. En las últimas décadas autores de distintas especialidades han señalado que la narrativa podría ser una modalidad básica de nuestra cognición. A lo largo de la historia, aprender a contar cuentos, crear fábulas y transmitir moralejas, pudo resultar una habilidad clave para quien deseaba definir y condicionar las prácticas sociales de una comunidad. Siguiendo estos lineamientos, Burkert afirma que los cuentos tradicionales y los mitos, vendrían a cumplir la función de transmitir, de forma sintética y pregnante, información vital para la supervivencia individual y del grupo. Pero además, afirma que existen ciertas constantes estructurales que determinan el modo en que organizamos la trama de cualquier historia.

Burkert basará su propuesta en los estudios que hiciera el folklorista Vladimir Propp sobre los cuentos tradicionales rusos. Tras un análisis riguroso y sistemático de una variedad de cuentos tradicionales de su país, Propp constató que ciertos patrones de organización estructural se repetían en todos ellos. Según Burkert estos patrones serían extensibles a casi cualquier producción narrativa. Lo que intentará demostrar es que en todas ellas se encuentra presente una arquitectura más o menos similar a la descripta por Propp. El principio organizador del cuento, dirá luego, el alma del argumento, pareciera operar, de un modo más o menos universal. Dicho patrón parece expresar para Burkert una modalidad básica de organización cognitiva.
\end{abstract}

Palabras Clave: Cuento Tradicional, Motifemas, Formalismo, Cognición.

\begin{abstract}
In this paper we have proposed to discuss and analyze the proposal of the philosopher Walter Burkert in light of the considerations made by different narratologists regarding the role of the narrative as a cognitive ability. For Burkert, the emergence and survival of certain cultural artifacts such as myths and traditional stories can be explained by the effectiveness and efficiency they express as tools to store and transmit information relevant to the species. Among the virtues and potentialities that have stories and simple stories we can note that they are easy to remember.

In the last decades authors of different specialties have pointed out that narrative could be a basic modality of our cognition. Throughout history, learning to tell stories, create fables and convey morals, could be a key skill for those who wanted to define and condition the social practices of a community. Following these guidelines, Burkert affirms that traditional stories and myths would come to fulfill the function of transmitting, in a synthetic and pregnant way, vital information for individual and group
\end{abstract}

* Autor correspondiente / Corresponding author: dduero@ gmail.com 
survival. But in addition, it affirms that certain structural constants exist that determine the way in which we organize the plot of any history.

Burkert will base his proposal on the studies made by the folklorist Vladimir Propp on the traditional Russian stories. After a rigorous and systematic analysis of a variety of traditional stories from his country, Propp found that certain patterns of structural organization were repeated in all of them. According to Burkert, these patterns would be extendable to almost any narrative production. What he will try to show is that in all of them there is an architecture that is more or less similar to the one described by Propp. The organizing principle of the story, he will say later, the soul of the argument, seems to operate, in a more or less universal way. This pattern seems to express for Burkert a basic modality of cognitive organization.

Key Words: Traditional Tale, Narrative Analysis, Cognition.

\section{LAS "FUERZAS FORMATIVAS" DE NUESTRA COGNICIÓN}

Como reconoce Walter Burkert (2009), en condiciones normales, la pura adición de conocimiento individual, superaría muy pronto la capacidad de cualquier sistema vivo para registrar lo que sucede en su entorno. Resulta esperable que, frente a la acumulación siempre creciente de datos, los organismos procuren acotar la experiencia. En ello mismo consiste el acto cognoscitivo. En el caso de los seres humanos, los procesos simbólicos nos ayudan a simplificar pero a la vez a estabilizar el mundo y volverlo predecible a fin de ajustar a él nuestros comportamientos.

Basándose en ciertas ideas neodarwinistas de la sociobiología y discutiendo con nociones como las que propone Richard Dawkin (1993) en su libro "El gen egoísta", Burkert intentará explicar el surgimiento y la supervivencia de ciertos artefactos culturales, como los mitos, los cuentos tradicionales o determinados símbolos que parecen ser más o menos universales. Sin decir que los genes prescriban cultura, este autor nos propone en cambio que es posible que impartan ciertas "recomendaciones" para la replicación de determinados patrones de interpretación y acción. Pareciera ser que la arquitectura de la mente animal y humana se organiza en función del reconocimiento de patrones perceptivos y comportamentales (Eibl-Eibesfeldt, 1993). Ello es así porque la identificación y producción de unos y otros, respectivamente, constituye un modo particularmente económico y efectivo para procesar, almacenar, usar y transmitir información relevante. Burkert habla de formas precondicionadas, de atractores que facilitarían la codificación, almacenamiento y posterior recuperación y recreación de información que podría ayudar a facilitar la adaptación. Sostiene que algunos artefactos culturales que parecerían estar especialmente asociados con necesidades humanas básicas y que promueven el propio ajuste dentro de un contexto esencialmente cambiante, responderían a este tipo de condicionantes. Se trataría de principios organizadores relevantes para la identificación y programación de secuencias de conductas especialmente significativas para la vida y la reproducción.

Burkert niega que exista alguna clase de marcador génico primario capaz de explicar los comportamientos sociales y culturales humanos en su conjunto. Sería probablemente demasiado fácil, nos previene, postular por ejemplo la existencia de una multiplicidad de imágenes arquetípicas que se activasen a partir de procesos innatos precodificados, para a partir de allí explicar disposiciones como la que el humano muestra hacia la religiosidad, por ejemplo. Ahora bien, sin llegar a suponer un mecanismo automático, es sugerente pensar que ciertas pautas de transmisión cultural podrían invocar algunos procesos "facilitadores", predisposiciones para incorporar y transmitir al menos alguna clase de conocimiento, de forma compacta y eficaz.

La tradición es siempre información condensada y sistematizada (Dawkins, 1993). En tal sentido, hay fenómenos que parecen resultar esenciales, fundantes a la vida de todos los seres humanos, por lo cual su consideración posee una especial relevancia más allá de cualquier tiempo y geografía. Se trata de fenómenos que son más o menos universales. Hallar formas de transmitir, sintética y eficazmente, información sobre esta clase de hechos, podría resultar clave en términos tanto biológicos como culturales. Así por ejemplo, dice Burkert, "en todas las partes la gente come, bebe, defeca, trabaja y duerme, disfruta del sexo y procrea, enferma y muere, es decir, es imposible negar el carácter general o biológico de estos 
procesos" (2009, p. 19). No es descabellado, entonces, suponer que la facilitación de determinados mecanismos para procesar y propagar información relevante con relación a cada uno de estos fenómenos, resultare ventajosa para la especie. No sería además casual, que este tipo de problemas vitales funcionen como sustento para la organización de cualquier actividad cultural más compleja, pues de su consideración parece depender la vida misma. Es presumible, dice Burkert finalmente, que determinados artefactos culturales busquen optimizar el procesamiento de información relevante favoreciendo determinadas estrategias cognitivas, estados emocionales y prácticas simbólicas que ya han dado muestras de ser pertinentes en el pasado para organizar nuestras conductas y promover la adaptación. Dicho en pocas palabras: lo que es funcional se vuelve con el tiempo tradición.

\section{FACTORES CONSTRICTIVOS E INFORMACIÓN}

Burkert (2009) cree que ciertas funciones controlan, biológica pero además socialmente, nuestro flujo de información. Es sugestivo pensar que del surgimiento de algunas instituciones sociales, como la religión o nuestro sistema legal, resultara la capacidad humana para garantizar cierto ordenamiento del mundo junto a la cohesión de la comunidad, durante largos períodos de tiempo. En un nivel muy básico, el caso del lenguaje resultaría paradigmático de lo que sería un sistema instituido para codificar y simplificar la información sobre nuestro entorno ecológico y social. La aparición del lenguaje como herramienta para codificar y comunicar experiencias significativas, junto con la posibilidad de favorecer el ordenamiento subjetivo, parece haber dado lugar al advenimiento de un mundo mental común entre los seres humanos. Nuestro lenguaje nos permite no sólo coordinar acciones y compartir sentimientos sino también transmitir pensamientos, planes, conceptos y valores comunes que permiten la coordinación grupal.

Algo que no parece casual es que todas las lenguas se organicen fundamentalmente en base a dos tipos de sentencias: aquellas que comunican información y las que imparten órdenes (siendo probablemente las segundas las más antiguas en aparecer). En todas las lenguas, además, los verbos parecerían funcionar como organizadores lingüísticos primarios. El verbo permite ordenar en una secuencia dos estados de cosas, o bien describir un devenir, y establecer un contraste entre estabilidad y cambio (o entre las acciones y sus efectos). El ordenamiento oracional a partir del verbo remarca, la mayoría de las veces, el contraste entre cómo estaban las cosas en el mundo hasta ahora y cómo están o son a partir de este momento. En la relación entre sustantivo y verbo hay un interjuego entre lo que permanece idéntico a sí mismo y lo que se modifica, entre lo que es y lo que se hace (Duero, 2017) $)^{1}$.

Respecto de esto, cabe señalar que existe un modo particular de configurar u ordenar la experiencia, al parecer específico de la mente humana y que se halla intrínsecamente ligado con ciertas competencias lingüísticas más o menos complejas que aparecen en el niño después de los tres años y medio. Estas capacidades le permiten, entre otras cosas, construir oraciones intercalando sujeto y predicado; establecer relaciones de causa y efecto; identificar secuencias temporales antes-después; adscribir intencionalidad y propósito a ciertos agentes e identificar relaciones entre medios y fines, etc. Todas estas competencias acompañan la aparición casi simultánea de cierto interés infantil por oír y construir historias y por averiguar el porqué de cada cosa.

\section{LA POTENCIA DE UNA HISTORIA}

Una pregunta clave, que la psicología debe aún responder, es si es o no apropiado reducir y tratar de explicar las diferentes formas de cognición humana únicamente desde lo que han propuesto los modelos cibernéticos dominantes. Las primeras teorías cognitivistas se fundaron en una concepción computacional del psiquismo; dichas teorías, homologaban la mente con un sistema de procesamiento de la información semejante a una máquina de Turing o a un ordenador. Durante los años 60 el desarrollo de los ordenadores digitales, la nueva lingüística generativa y la crisis profunda del conductismo, entre otros factores, propiciaron el surgimiento de este paradigma simbólico-computacional. Por primera vez los procesos mentales parecían poder explicarse a partir de modelos mecanicistas. Los símbolos, las reglas sintácticas y los cómputos subyacentes a los procesos mentales resultaban entidades perfectamente mensurables. Se propulsó así un programa que abogaba por el desarrollo de una ciencia cognitiva general que englobara el estudio 
de los procesos computacionales junto con el de los sistemas biológicos. Ello implicaba, claro, pagar un precio alto: se debía restringir los procesos psicológicos a la noción de cómputo, implícita en la tecnología computacional. De este modo, las funciones cognitivas de la mente humana pasaron a ser equiparadas a las funciones computacionales de los ordenadores (De Vega, 1998).

En los ochenta y a comienzo de los noventa, Jerome Bruner supo cuestionar el paradigma computacional (1987, 1991a, 1991b). Por entonces este autor comienza a hacer notar que nuestras competencias narrativas podrían ser expresión de una capacidad más o menos primaria para procesar, almacenar e interpretar información. Para Bruner, los relatos serían un recurso cognitivo diferente del postulado por los modelos algorítmicos tradicionales. Su propuesta fue, claro, un intento por distanciar a la psicología cognitiva clásica de los modelos representacionales predominantes (véase también Di Paolo, 2005, 2009, 2010; Menary, 2006, 2008).

Para Bruner los relatos surgirían como un intento por ordenar lo impredecible, lo sorpresivo y lo caótico de la experiencia. Para ello insertamos los acontecimientos, sobre todo si son inesperados, dentro de una trama que nos permite comprender su evolución, leyéndolos además en función de su implicancia para personajes que actúan en base a motivos y razones (Bruner, 2003). Lo que Bruner sostenía, es que nuestras habilidades narrativas podían constituir un tipo de esquema organizador básico, útil para optimizar nuestro conocimiento del mundo social.

Dice Burkert respecto de esto:

Desde Aristóteles se ha dado generalmente por sentado que el conocimiento adopta la forma lógica de afirmaciones, predicados sobre un sujeto. El mundo es una totalidad de hechos, escribió Wittgenstein. Sabemos, porque lo hemos aprendido, que es el caso y es verdad que la ballena es un mamífero y no un pez, que el relámpago es un fenómeno de electricidad y que St. Andrews es una ciudad de Escocia. (Burkert, 2009, p. 107).

Esta modalidad de cognición supone una forma útil, pero limitada de conocimiento. Lo que aprendemos cuando escuchamos una historia, es que las cosas evolucionan, muestran un desarrollo, que los actos conllevan a diferentes consecuencias, etc. Un relato nos enseña por ejemplo,

que determinada persona hizo esto o aquello, y éste fue el resultado. Es difícil explicar cómo se puede generalizar ese conocimiento tan personal, pero sin embargo se puede decir que tales historias son comprensibles; provocan empatía; con frecuencia dominan la comunicación. El cuento es la forma a través de la cual una experiencia compleja se vuelve comunicable. (Burkert, 2009, p. 108).

Entre las virtudes y potencialidades que tienen los cuentos y las historias simples podemos señalar que, quizá porque generan ciertas disposiciones anímicas facilitadoras, son sencillas de recordar. Algo que los psicólogos saben es que mientras una sucesión de palabras inconexas (como por ejemplo: “cuadro, mujer, sillón, lámpara, perro, disparo, ladrido, terraza, habitación, teléfono, cable"), resulta difícil de evocar, los mismos términos puestos dentro de un microrrelato pueden ser rememorados con relativa holgura. (La anterior lista de palabras, por caso, podrá recordarse con bastante exactitud si construimos con todas ellas una pequeña historia como: "Bajo el cuadro de la mujer, en el sillón, junto a la lámpara, el hombre acariciaba a su perro cuando oyó el disparo. El perro dio un ladrido. El hombre salió a la terraza. Regresó a la habitación. Tomó el teléfono para pedir auxilio. ¡Pero el cable estaba cortado!”). E igual cosa ocurre con cuestiones más complejas como recordar un mandato, una orden, un consejo que debe ser tenido en cuenta durante un período de vida relativamente largo, etc. Si la consigna forma parte de un relato cuyo desenlace nos deja alguna enseñanza, tiene mayor probabilidad de ser conservado en nuestra memoria.

Quizá todo esto tenga que ver con que una historia produce en quien la escucha una experiencia más o menos vívida, además de cierto grado de comprensión y empatía para con sus personajes. Es decir, una historia conlleva un recuento de hechos a la vez que nos involucra y compromete emocionalmente. Al oír un relato generamos expectativas; esperamos que ciertas cosas sucedan; nos indignamos con los actos de algunos personajes que nos parecen deshonestos; sentimos que determinadas consecuencias son merecidas o inmerecidas; abogamos por los desenlaces más o menos favorables según nuestro sentido de la 
justicia y quedamos, en definitiva, expectantes, complacidos o frustrados, en función de cuál haya sido el desenlace de la trama.

\section{4. ¿UNA COGNICIÓN NARRATIVA?}

En las últimas décadas autores de distintas especialidades han venido señalando que la narrativa podría ser una modalidad irreductible de nuestra cognición (Baumeister \& Newman, 1994; Herman, 2002, 2003, 2009; Palmer, 2004, 2010). Danto (1989) cree que aportamos inteligibilidad a los hechos del mundo insertándolos en el marco de una historia; que al conformar una historia hacemos que los hechos se vuelvan significativos. La narración sería la primera fase, indispensable, dice, de cualquier intento de explicación de un conjunto de actos humanos. En tal sentido, aunque no siempre hagamos relatos explícitos, cuando nos preguntamos por ciertos vínculos entre hechos diversos o cuando tratamos de entender por qué ocurrió lo que ocurrió; cuando nos preguntamos ¿Qué está pasando? Y luego ¿Por qué algo ha sucedido?, contaríamos ya con los gérmenes de un relato (Eco, 2013).

Por cierto, en la vida diaria podemos construir explicaciones que no supongan narraciones o nada más describir una serie de acontecimientos sin darles la forma de una historia acabada. Cuando se trata de asuntos humanos, sin embargo, pareciera ser que por detrás de lo que lleguemos a expresar, se encuentra siempre la aspiración a unificar los acontecimientos narrativamente (White, 1973). Para ello, éstos han de ser vinculados con agentes; esos agentes han de ser capaces de experimentar la realidad vívidamente; han de desplegar actitudes intencionales; deberán actuar en base a motivos y razones, etc., todo esto a fin de que los hechos adquieran realmente inteligibilidad (Hermans, 2006; Mc Adams, Hoffman, Mansfield, \& Dray, 1996).

Para Ricoeur $(1978,2004)$ la inteligibilidad que aporta la trama de un relato al momento de significar un conjunto de acciones y experiencias, halla su primer anclaje en nuestra competencia para utilizar de manera significativa una red conceptual que supone una teoría nä̈ve de la acción humana y que, entre otras cosas, parte de diferenciar la acción del movimiento físico. Es decir, todo relato supone una serie de postulados implícitos sobre cómo nuestras acciones conllevan a ciertos fines, cómo ciertos actos pueden hallarse mejor o peor justificados según tales o cuales motivos y razones, etc. En esta red, cada término cobra sentido según cuál sea su relación con los demás términos y cuál sea la función que cumpla dentro de esa totalidad orgánica que es el relato. Las sentencias "Juan disparó a su padre por codicia" y "Juan disparó a su padre por piedad" contribuyen a aportarle al acto de matar dos sentidos completamente distintos, un asesinato en el primer caso, y tal vez una eutanasia o un acto de misericordia en el segundo. Ello es así porque cada acción, dirá Ricoeur, obtiene su plena significación de los demás términos de toda la red. Es decir, la acción no es solo un movimiento físico; incluye ya en su definición un trasfondo de motivos y razones o propósitos ${ }^{2}$ (Duero, 2017).

Ricoeur cree que a la forma de describir acciones y a los modos de ordenar una secuencia narrativa subyace un mecanismo común. Podríamos pensar incluso que el cuento es un modo de condensar de forma eficaz, instrucciones sobre cómo actuar y enseñanzas sobre cómo interpretar lo acontecido. Con relación a ello, algo que cabe preguntar es si nuestros planes de acción no vendrían a ser la contracara de un relato; es decir, si sería aceptable suponer que la composición de la trama de un relato se enraíza en esta forma de precomprensión del mundo de la acción (Ricoeur, 2004). Algo que parece evidente es que nuestros planes de acción al igual que los relatos suponen describir una secuencia de comportamientos, con una evolución y un desenlace que puede resultar más o menos satisfactorio, en función de cuáles hayan sido las intenciones que los guiaron; que los relatos sean narrados en tiempo pasado y los planes de acción en tiempo futuro podría no ser más que un elemento subsidiario (Duero, 2017).

\section{NECESIDAD DE HISTORIAS}

Como dijimos antes, un relato es un intento por responder a dos preguntas: ¿Qué está pasando y por qué? Para Bruner (1991, 2002), una historia busca: o resaltar un acontecimiento o conjunto de acontecimientos; o explicar por qué ha ocurrido algo relativamente extraordinario; o bien indicar lo que es esperable o recomendable que hagamos en determinadas situaciones más o menos límites o ciertamente atípicas. Es decir, el relato surge como un intento por lidiar con un estado de intriga y desorientación. La historia funciona precisamente por la expectativa que crea el hecho sorpresivo ¡Nadie cuenta una historia sobre lo que 
es habitual o sobre lo que todo el mundo sabe! Tras la situación de excepcionalidad y sorpresa, las acciones de los protagonistas se nos ofrecerán siempre como un intento de superar una infracción, recobrar un estado original de equilibrio o al menos hacer una denuncia sobre lo que ha acontecido (Bruner, 2002). La trama será el dispositivo que nos permita unificar aquel conjunto de elementos variables, muchas veces caóticos e impredecibles, aportándoles un sentido y una orientación.

La efectividad del relato dependerá de cómo esté organizada esa historia. Toda trama posee una estructura así como elementos característicos que hacen a su potencia: uno o más actores, una serie de acciones, una meta, un escenario, un instrumento, etc. La trama requerirá además de un obstáculo o problema que resulte de un desequilibrio entre cualquiera de los elementos previos (Burke, 1945). A la vez la historia proveerá herramientas para armonizar lo sucedido o al menos sacar una enseñanza de ello. Los relatos trazan así un contrapunto entre desequilibrio y armonía.

Conjuntamente, las buenas narraciones suelen contener un prefacio, introducción o resumen, más algunas cláusulas de orientación, con las cuales se establecen las características de los personajes y se especifica el tiempo, el lugar y las circunstancias en que ocurre el relato. Tienen además cláusulas narrativas, que hacen al esqueleto mismo de la narración y nos cuentan lo que finalmente sucedió en los momentos claves del relato (Linde, 1993). Finalmente, suelen incorporar, de forma explícita o no, una especie de epílogo que invita a alguna forma de evaluación o conclusión respecto de la historia (Duero \& Limón Arce, 2007).

Veamos un ejemplo. Alguien dice: "Damián se sintió traicionado en su buena fe y salió a buscar revancha tratando de destruir a Abel". Lo que tenemos aquí es un microrrelato que nos abona un marco hermenéutico a partir del cual interpretar las conductas vengativas de Damián. Por cierto, ningún comportamiento concreto agotaría las posibilidades de lo que se dice es "tomar revancha", lo que puede incluir desde destruir a Abel económicamente hasta seducir a su mujer o asesinarlo. Antes que una explicación de una conducta concreta, nuestra narración nos ofrece un trasfondo a partir del cual leer los actos pasados y futuros del protagonista a fin de hallarles un sentido y superar la intriga. Dicho trasfondo incluye los motivos y propósitos así como también los acontecimientos previos (la traición o deslealtad de Abel, supongamos), que justifican o explican las disposiciones actuales de Damián. Se trata de un modelo explicativo aunque de naturaleza diferente a otros modelos de explicación tradicionales (Danto, 1989; Ricoeur, 1978; White, 1973). Ante lo que estamos es ante un intento por reconstruir el encuadre psicológico, los esquemas interpretativos y la orientación general que expresa un agente. Para ello atendemos a la evolución de ciertos acontecimientos y las consecuencias que los mismos supusieron para aquél. Según creemos, todo lo anterior vuelve al relato una herramienta imprescindible, especialmente útil para dar sentido y configurar los actos humanos. En su esencia, el relato vendría a ser un arma de reducción y validación, que nos ayuda a identificar problemas, a negociar situaciones y sacar conclusiones sobre lo que ha acaecido (Burkert, 2009).

Por cierto, en los últimos años, diverso narratólogos y psicólogos han sugerido que fenómenos como el sentido de identidad personal, podría ser consecuencia de la facultad del ser humano para organizar la información en la memoria de un modo narrativo y autobiográfico (Tulving, 1983). De acuerdo con esta tesis, la identidad personal sería menos resultado de "algo" que descubrimos dentro nuestro, mediante un trabajo de introspección, que una ficción que elaboramos para dar coherencia y continuidad a nuestra experiencia cotidiana, que de otro modo resultaría caótica, impredecible y desconcertante. $\mathrm{Al}$ evocar cualquier experiencia autobiográfica, lo que hacemos es reconstruirla insertándola dentro de una diacronía que involucra una secuencia de hechos y acciones con respecto a la cual nos ubicamos como protagonistas (Gallagher, 2000; Hermans, 2006, 2006). Al hacerlo, tratamos el desarrollo de los eventos como si de por sí tuvieran, intrínsecamente, un sentido y una dirección. Pero es gracias a tal trabajo de reconstrucción, de hecho, que esa cronología alcanza a constituirse como una totalidad unitaria.

De acuerdo con la tesis de diferentes narratólogos, cada vez que decidimos incluir o excluir un acontecimiento o una acción como parte de una historia, estamos condicionando su sentido y el modo en que su desenlace habrá de connotarse (Danto, 1989; Herman, 2002; Lavov \& Waletsky, 1967). En el caso de los relatos autobiográficos esto tendría profundas consecuencias con respecto del modo en que nos concebimos y al sentimiento que 
desarrollamos respecto de quienes somos (Adler \& McAdams, 2007; McAdams, 1995; McAdams, Hoffman, Mansfield, \& Dray, 1996).

Distintos estudios sugieren, cabe decir, que las narrativas autobiográficas ricas y coherentes se asocian con rasgos de personalidad más saludables y que, en cambio, ciertos patrones narrativos disruptivos estarían más frecuentemente asociados con síntomas de patología mental (Adler, Wagner, \& McAdams, 2007; Capella, 2017; McAdams, Anynidoho, Brown, Huang, Yi, Kaplan, \& Machado, 2004). Dimaggio y Semerari (2001), han señalado respecto de esto, que las narrativas bien construidas permiten a las personas desarrollar una visión mejor integrada de la realidad y de sí mismas. Cuando una narrativa autobiográfica es coherente, provee un sentido de orientación así como un marco de motivos y razones para comprender las acciones de los distintos personajes; también suele aportar indicadores sobre por qué o con qué fin se cuenta dicha historia; todo ello ayuda a su autor a saber qué esperar y cómo posicionarse respecto del mundo. En cambio, las narrativas incoherentes o disruptivas no permiten arribar a una perspectiva compleja, ni a una conclusión clara y consistente sobre la realidad y los personajes que la pueblan. Entre otras cosas, las narrativas pobres e incoherentes suelen ofrecer una caracterización negativa e imprecisa de sus protagonistas. También expresan una mayor tendencia a polarizar y simplificar a los distintos personajes. La visión sobre el futuro que sus autores nos presentan, por lo demás, suelen ser imprecisas e indefinidas (Adler, Chin, Kolisetty, \& Oltmanns, 2012; Bamberg, 2012; Duero \& Osorio, 2018; Mc Adams et al., 2004; Salvatore, Conti, Fiore, Carcione, Dimaggio. \& Semerari, 2006).

\section{LA PREHISTORIA DEL RELATO}

¿Cómo es que los hombres comenzamos a construir relatos y qué implicancias pudo tener ello sobre los modos de conservar y transmitir distintas pautas culturales y organizar nuestra propia subjetividad? “No saben lo que me pasó?”, suele ser una expresión típica de cualquier persona dispuesta a relatarnos una historia sobre un acontecimiento que le resultó más o menos excepcional y movilizador. Parecería legítimo suponer que el ser humano comenzó a contar cuentos más o menos en el momento en que desarrolló la capacidad de hablar. Es muy posible que en sus orígenes estos relatos, de carácter meramente informativos, no hayan recibido título alguno. "Se contaban simplemente para marcar un acontecimiento, dar un ejemplo, advertir sobre un peligro, obtener alimentos, o explicar lo que parecía inexplicable. La gente relataba historias para comunicar conocimiento y experiencia en contextos sociales", dice Jack Zipes (2014, p. 23). Con todo, aprender a contar cuentos, crear fábulas y transmitir moralejas, pudo resultar una habilidad clave para quien deseaba definir y condicionar las prácticas sociales de una comunidad. El empleo del lenguaje y de los cuentos pudo habernos permitido, seguramente, promover diferentes formas de cognición y propulsar y favorecer ciertos programas de acción por sobre otros. Por ejemplo,

si en la Edad de Piedra un hombre regresaba sano y salvo de una expedición al bosque donde se había enfrentado a una bestia monstruosa y le había dado muerte, su mente habría estado preocupada por este encuentro y habría querido relatar su experiencia a los demás integrantes de su clan como hecho histórico o advertencia. Sin duda, habría usado una particular forma simple de narración para relatar aspectos salientes de su encuentro, como una anécdota, fábula, exemplum, proverbio o cuento de hadas. O podría haber combinado las formas para narrar. Lo que era y sigue siendo fundamental para este narrador (y para todos los narradores) es darle a su cuento una forma tal que cobre vida, se vuelva efectivo y relevante. De hecho su propósito era y es hacerse relevante. (Zipes, 2014, pp. 37-38).

Según Drout, mediante la tradición oral se transmiten unidades de información con forma de universales culturales que permiten ajustar nuestros actos al mundo. Los elementos clave, aquí, son la repetición y la memoria. Mediante la repetición se crean patrones fáciles de codificar y almacenar. Como dijimos, los cerebros humanos parecen tener una capacidad exacerbada para reconocer patrones. "La habilidad humana para reconocer patrones supone que en una cultura que incluye tradiciones que se repiten, la información puede codificarse y transmitirse de una manera comprimida" (Drout, 2006, p. 271). De esta forma ciertos patrones codificados por la tradición pueden ser eficazmente comunicados ayudando a la autorregulación de otros miembros de nuestra comunidad. 
Para Zipes, muchas de estas unidades informacionales resguardadas por la tradición habrían pasado a formar parte de los mitos, las fábulas y los cuentos tradicionales. Es de suponerse que las historias que han sobrevivido al tiempo y se han vuelto más o menos tradicionales, posean su atractivo precisamente porque guardan cierta pedagogía y condensan información relevante que es también universal en mayor o menor grado. Los cuentos al igual que los mitos y las fábulas nos revelarían, dice este autor, verdades sobre la condición humana, sobre nuestras carencias, sobre la posibilidad de descubrir alguna armonía en el mundo, sobre lo que son las relaciones de poder, sobre la importancia de la reciprocidad en los vínculos, etc. Las fábulas, por ejemplo, refieren y analizan las relaciones de poder asimétrico; alientan a quienes están oprimidos a hablar y denunciar cierta injusticia en códigos metafóricos, etc. Por ello,

son al mismo tiempo perturbadoras y esclarecedoras. No buscan predicar ni moralizar en el sentido estricto porque su propósito es revelar las contradicciones de la conducta humana más que dictar principios de conducta: explorar la conducta humana más que instruir. (Zipes, 2014, p. 44).

Sin embargo sutilmente, como ocurre con el cuento tradicional o el cuento de hadas, las fábulas también advierten y recomiendan. Y como aquellos, pueden transmitir una preocupación por nuestros códigos morales y el sentido de la obligación, así como prevenir con relación a temáticas humanas universales, como la rivalidad entre hermanos, la traición a la confianza, el abuso de poder, etc. (Campbell, 1959).

Con relación a ello, es notorio que en la mayoría de los relatos tradicionales de diferentes épocas y culturas, aparezcan nociones como por ejemplo, las de obligación mutua y consciencia de rango. En el primer caso lo que se señala es el principio de reciprocidad como clave para mantener cierta armonía grupal. En el segundo, lo que se acentúa es la importancia del respeto por las jerarquías para conservar un determinado orden. Se acepta la existencia de un sistema de rangos en donde hay un dominador y un dominado, el amo y el esclavo, el rey y el vasallo. Cualquier forma de relación de dominación supone, sin embargo, un vínculo que aunque asimétrico implica a su vez un conjunto de obligaciones mutuas entre las partes. Es el respeto de esas obligaciones lo que asegura la estabilidad y la armonía del conjunto. Sobre este esquema se instaura un contrato que establece lo que es justo e injusto para quien somete y para quien es sometido. La lealtad y la sumisión del siervo deben ser recompensadas por el reconocimiento y la magnanimidad de su señor. En caso contrario, el contrato se rompe y es preciso hallar una explicación y, también, una resolución de la situación que ponga fin a la historia restituyendo las condiciones del contrato.

\section{LA IMPORTANCIA COGNITIVA DE LOS CUENTOS TRADICIONALES}

Siguiendo estos lineamientos, Burkert (2009) insiste en que ciertas historias, como los cuentos tradicionales y los mitos, vendrían a cumplir la función de transmitir, de forma sintética y pregnante, información vital para la supervivencia individual y del grupo. Una historia memorable, dice Burkert, es siempre y ante todo una estructura de sentido.

Burkert basará su propuesta en los estudios que hiciera el folklorista Vladimir Propp (1971) sobre los cuentos tradicionales rusos. Propp (1971) supo señalar, hace ya casi un siglo, que para comprender el origen de los cuentos tradicionales, es preciso comprender sus intervínculos con la vida práctica y con la religión. Para Propp, ciertas representaciones religiosas con alguna funcionalidad práctica, se volcaron en los mitos e incluso, sobre ciertos rituales (ya que en última instancia, una ceremonia ritual podría no ser más que un contenido mitológico transmutado en acción). Posteriormente, esas historias se metamorfosearon en cuentos tradicionales.

Propp dirá que es posible comparar el estudio de los cuentos con el de las formas orgánicas naturales; como el naturalista, también el folklorista y el narratólogo procuran identificar géneros y especies, basándose en el supuesto de que tras lo variable, puede uno descubrir alguna forma estructural que se mantiene constante. Las partes constitutivas, dice Propp, son las que mejor se prestan a la comparación. En zoología, esto equivaldría a comparar las vértebras o los dientes de distintos animales entre sí. Esas semejanzas pueden buscarse también en el relato; puede hacerse comparando sus argumentos o teniendo en 
cuenta otra clase de unidad de medida, atendiendo por ejemplo a su composición y estructura, o más específicamente a las funciones que los distintos personajes cumplen.

Tras un análisis riguroso y sistemático de una variedad de cuentos tradicionales de su país, Propp constató que ciertos patrones de organización estructural se repetían en todos ellos. Es decir que todos los cuentos se ordenaban en base a una configuración primaria más o menos análoga. Propp afirma que es posible identificar en todos los cuentos maravillosos rusos 31 funciones o motifemas (esto es, una secuencia de acciones con sus respectivas consecuencias) que se repiten otorgando una estructura formal más o menos idéntica a todas las historias. Algunas de estas acciones u operaciones son: la prohibición, la transgresión, la fechoría, la partida del héroe, el combate y la prueba o tarea difícil que el héroe debe superar, el engaño, la revelación del engaño, el castigo al villano y el reconocimiento del héroe, etc.

Propp procuró fraccionar y segmentar las historias tradicionales en una secuencia de acciones factible de ser enunciada mediante predicados o sintagmas narrativos tales como: los padres parten hacia el bosque, prohíben a los hijos salir de casa, el dragón rapta a la doncella, etc. Tales predicados hacen a la estructura del relato, en tanto que los sujetos, complementos y demás partes configuran el argumento (Mélétinski, 1971). Mientras que estos sintagmas narrativos definen las funciones o motifemas, elementos constantes, que se repiten, sino en su totalidad, al menos sí en su secuenciación en todas los cuentos tradicionales, los demás elementos pueden variar dotando a cada historia de aspectos idiosincráticos (motivos, argumento, etc.).

$\mathrm{Al}$ aislar las funciones de los personajes, dice Propp, es posible descubrir los aspectos del cuento que se repiten en esencia más allá de la apariencia. El envío y la partida del héroe o protagonista, por ejemplo, son siempre constantes igual que lo es la situación de pérdida o carencia que hace a la situación inicial de casi todos los cuentos (lo cual además funciona como motor de la trama). En cambio, quién envía y quién parte, son aspectos variables. La tesis de Propp es que estas funciones u operaciones, que pueden ser llevadas a cabo por distintos personajes y en distintos momentos de la historia, son elementos constantes de todos los cuentos tradicionales; Propp postula además que el número de estas funciones es limitado y que aunque no es necesario que todas las funciones aparezcan en cada relato, su secuencia es siempre la misma. A modo de ejemplo, y para hacer una simplificación de la estructura proppeana a sus elementos más primarios, las historias suponen en su inicio una violación, una alteración o bien un desafío que altera el orden de la comunidad y obliga al héroe a partir a la aventura. Durante su andanza, el héroe debe realizar ciertas pruebas que ponen en juego su integridad. Una vez que ha salido airoso debe regresar a la comunidad reintegrando la armonía perdida. Entonces está listo para obtener un merecido reconocimiento. En cada secuencia identificada, hay una clara instrucción sobre cómo es recomendable que reaccionemos ante la adversidad. El héroe representa una ética, un conjunto de indicaciones sobre cómo es esperable conducirse.

Propp ha identificado además, una serie de procedimientos mediante los cuales es posible explicar las aparentes variaciones entre distintos cuentos. Algunos de estos procedimientos son: 1) la reducción: en lugar de la descripción de un elemento completo de la historia, se menciona sólo una parte; 2) la ampliación, que sería el fenómeno opuesto; 3) la deformación, esto es, la trasfiguración de alguno de los elementos narrativos; 4) la inversión: que supone transformar las imágenes en sus contrarios, por ejemplo, el héroe masculino en femenino; etc. Cada una de estas transformaciones puede obedecer, dice Propp, a la imaginación del cuentista o bien a condicionantes sociales, históricos y geográficos que inciden sobre el ajuste o adaptación de la historia a determinadas condiciones locales. Esas variaciones no afectan jamás, sin embargo, a los aspectos estructurales primarios, que el narratólogo podrá reconocer sin gran dificultad a partir del análisis formal.

Algunos continuadores de la obra de Propp, como Dundes (s/r, en Mélétinski, 1971), han propuesto que entre las funciones, sería posible identificar ciertas parejas de motifemas esenciales o nucleares. Así por ejemplo, sucede con la $\mathrm{ca}$ rencia, que parece estar presente en casi todas las historias, y que supone de hecho o virtualmente, la instancia posterior de reparación. Explorando estos intentos de reducción de las 31 funciones de Propp a sus elementos formales más básicos, Serebriany (s/r, en Mélétinski, 1971), señala que todo cuento tradicional puede dividirse en tres 
momentos fundamentales: 1) la fechoría inicial que crea el nudo o la intriga; 2) las acciones del héroe como respuesta a la fechoría y; 3 ) el desenlace feliz, que consiste en el restablecimiento del orden de las cosas ${ }^{3}$. Algo a dilucidar es si este esquema no se halla presente prácticamente en cualquier tipo de construcción narrativa que podamos llegar a elaborar.

\section{EL CUENTO Y EL MITO}

Lévi-Strauss (1991) ha llamado la atención sobre dos hechos importantes con relación a la tesis de Propp. Lo primero a lo que atiende Lévi-Strauss es a que Propp haya centrado sus investigaciones en el análisis de un tipo de cuento particular: el tradicional. ¿Es posible, dice el antropólogo, preguntarse qué razones incitaron al autor ruso, a elegir esta clase de cuento popular para su análisis y para poner a prueba su modelo? Para aquel narratólogo, una vez que se reduce a su crasa morfológica, el cuento tradicional se vuelve asimilable al mito. Y la verdad es que Propp está en lo cierto, dice Lévi-Strauss. "No hay ningún motivo serio - afirma - para aislar los cuentos de los mitos" (1991, p. 47), ya que en efecto, agrega, todo mitólogo sabe que los relatos tradicionales se advierten, generalmente, como formas trastocadas de los mitos. Ocurre, nada más, que los cuentos suelen construirse sobre sistemas de oposiciones $\mathrm{y}$ articulaciones que, por estar basados en axiomas sociales y morales (como ser la idea de lo que sería correcto o incorrecto hacer o lo que pudieran ser las formas de lealtad y traición), resultan más débiles que las de los mitos (en donde tales oposiciones poseen conato metafísico, cosmológico o natural al menos). Además, los primeros se hallan menos supeditados a los requisitos de coherencia lógica, de ortodoxia religiosa y de presión colectiva. Y es también por ello mismo, que el cuento ofrece más posibilidades de juego y de permutaciones. Pero salvadas estas diferencias, sigue diciendo Lévi-Strauss - y con ello se adelanta en varias décadas a Burkert- los cuentos son mitos en miniatura, en donde las mismas oposiciones - que darán lugar a las distintas parejas de motifemas, por ejemplo partida/regreso- están transpuestas a escala reducida (Lévi-Strauss, 1991, p. 50).

Probablemente el error que ha cometido Propp, sugiere más adelante Lévi-Strauss, haya sido suponer una relación diacrónica entre los mitos y los cuentos. El etnólogo, dice, sabe que los mitos y los cuentos coexisten de forma simultánea y que los segundos no son nada más que una versión degradada de los segundos. Por el contrario ambos explotan una sustancia común, aunque lo hagan de diferentes modos. Por otra parte, agrega, la distinción que Propp hace entre forma (lo invariable) y contenido (lo variable) de los relatos resulta en ocasiones arbitraria y termina por aniquilar el objeto mismo del estudio. La forma y el contenido de un mito o un relato merecen el mismo tipo de análisis, dice Lévi-Strauss, pues el contenido extrae su realidad de la estructura y lo que se llama forma depende de la articulación pero también de la puesta en contexto de los distintos elementos de una historia. Dicho de otro modo: si quitamos a la forma el contenido, lo que nos queda es una abstracción que no representa ni un cuento ni un mito. Por el contrario, el sentido del cuento y del mito, depende no solo de las funciones a partir de las cuales es compuesto, sino también de lo que hace al contenido en un particular contexto que condensa e intensifica cierto sistema de oposiciones (operadores primarios, dirá en otro momento el antropólogo) que matizan pero a la vez fortalecen la estructura de la historia. Que una misma función sea llevada a cabo por un águila que aparece de día o un búho que aparece de noche, permite definir al águila como búho diurno y viceversa, apuntalando una oposición entre el día y la noche. Con ello, la misma función se modifica. Estas oposiciones definen y condicionan el universo en función del cual se orden la experiencia de un determinado grupo humano ${ }^{4}$.

\section{EL FUNDAMENTO COMÚN DEL MITO Y EL CUENTO}

Tal vez siguiendo las observaciones de Lévi-Strauss (aunque ello no se aclara en su obra) Burkert desarrolla y extiende la propuesta original de la tesis de Propp. Lo que Burkert propone es que los elementos identificados por el formalista ruso, serían extensible a la mayoría de los cuentos tradicionales, a los cuentos de hadas y a los mitos. Sugiere además que las diferentes presentaciones de los cuentos tradicionales, al igual que ciertos mitos, parecieran responder a un argumento más o menos similar, que es su fundamento. Postula finalmente que todos ellos suponen una cadena de motifemas que constituyen, en esencia, programas de acción, es decir, instrucciones sobre modos de actuar, reacciones y, también, sobre experiencias 
factibles de ser padecidas, a lo largo de una secuencia argumental.

Basándose en el análisis de mitos y cuentos de diferentes países y épocas, como la leyenda de Perseo, el mito de los Argonautas, la epopeya de Gilgamesh o el texto sumerio Ninurta y el Assaku, Burkert intentará demostrar que en todos ellos se encuentra presente una arquitectura más o menos similar a la descripta por Propp.

El patrón de Propp opera como principio organizador desde los cuentos más antiguos que se han registrado, pasando por la mitología clásica y mucho más allá. En realidad sería fácil (y tedioso) seguir las organizaciones de Propp a través de las novelas, el teatro y el cine modernos, la ciencia ficción y los juegos de ordenador. Da la impresión de que lo que actúa es una forma general y transcultural de organizar la experiencia. (Burkert, 2009, pp. 117-118, [énfasis propio]).

El principio organizador del cuento, dirá luego, el alma del argumento, pareciera operar, por lo menos en cierto grado, discutiendo con la biología. $\mathrm{Si}$ las narrativas dependieran exclusivamente de la cultura, sería esperable que surgieran formas muy diferentes de organización y, por tanto, distintos patrones narrativos en función de cada civilización. Sin embargo, la secuencia posible de motifemas pareciera ser asombrosamente persistente ${ }^{5}$. Para constatar lo dicho, basta con hacer un recuento de la estructura de los guiones de las películas de Hollywood de los últimos cincuenta años o, aún, atender a cómo construimos historias para dar cuenta de determinados hechos cotidianos. Toda búsqueda, toda motivación y toda acción, es un medio para resolver un problema que se expresa a través del cuento. La acción funciona como puente entre un antecedente y un consecuente, un estado que la precede y otro que la sucede.

Curiosamente, y esto es algo que llama nuestra atención, estos mismos elementos estructurales parecieran hallarse presentes ya, en los modos en que construimos buena parte de nuestras oraciones declarativas: por lo común y en esencia, la mayoría de nuestras oraciones declarativas suponen la descripción de una acción puesta en contexto. Esa acción articula al sujeto con el predicado. A la vez, anuncia una modificación en el estado de las cosas entre un momento previo y uno posterior. La secuencia sujeto-predicado implica esencialmente un cambio de estado, una progresión desde la estabilidad a la inestabilidad y, subsecuentemente, una vuelta a la estabilidad. En muchas ocasiones, además, ese cambio es consecuencia de una acción llevada a cabo por un agente intencionado: alguien hace algo; alguien se propone algo; alguien consigue (o no), algo. $\mathrm{O}$ bien algo sucede y alguien es afectado por lo que acaba de ocurrir (Lavov \& Waletsky, 1967). Luego, se arriba a un nuevo estado de cosas que puede ser más satisfactorio o no, que podemos lamentar o agradecer, etc. (Duero, 2017).

Por cierto, Propp (1971) mismo creía que todos los predicados reflejaban en su estructura la esencia del cuento y que todos los sujetos, complementos y demás partes de la oración definían en esencia su argumento. Posteriormente, Todorov (1975), propuso que el elemento primario, abstracto y universal presente en cualquier narración, sería la proposición, en la que puede reconocerse siempre un agente (una persona) y un predicado (una acción), así como alguna clase de desarrollo, que se inserta en una diacronía (Lavov \& Waletsky, 1967).

\section{DISCUSIÓN Y CONCLUSIONES}

Ronald Barthes dice que o bien todo relato es una simple repetición fatigosa de acontecimientos, en cuyo caso sólo se puede hablar de ellos remitiéndose al arte, el talento o al genio del relator- todas formas míticas al azar-, o bien posee en común con otros relatos una estructura accesible al análisis, por mucha paciencia que requiera poder enunciarla; pues hay un abismo entre lo aleatorio más complejo y la combinatoria más simple, y nadie puede combinar (producir) un relato, sin referirse a un sistema implícito de unidades y reglas. (1991, p. 66, [énfasis propio]).

Volviendo al autor ruso, por debajo de cualquier interés clasificatorio, literario o folclórico, lo que Propp se proponía realmente era identificar el protocuento, la arquitectura originaria, primaria, que daba forma al conjunto de cuentos tradicionales. Para Propp, la secuencia de motifemas sería, en esencia, la que determina la composición del cuento y, con ello, su estructura. Es decir que el orden de las funciones o motifemas compondría un esquema fijo; dicho esquema no podría estar jamás ausente en ninguna evolución de ese protocuento. Por lo 
anterior es que se debería considerar al conjunto de los cuentos maravillosos, como nada más una cadena de variantes de una misma estructura factible de ser identificada. La misma composición serviría de base para diferentes asuntos. Que un dragón rapte a una princesa, o bien que un diablo rapte a la hija de una campesino o de un pope, vendría a ser igual desde el punto de vista formal, más allá de cuál fuese el argumento de una historia particular. Vistos desde su composición, los distintos cuentos se nos presentan, creía él, como versiones de una morfología común reconocible bajo la heterogeneidad aparente sugerida por cada creación puntual.

En este trabajo y retomado la lectura que de Propp hiciera Burkert (2009), hemos propuesto que cierta modalidad de cognición podría sintetizarse y expresase, de un modo por demás compacto, en la capacidad humana para ordenar cierta secuencia de motifemas y en base a ella construir una narración o relato. La secuencia básica que ordenaría este tipo de composiciones permitiría describir un estado de desequilibrio inicial; un conjunto de acciones conducidas por un agente intencionado (las cuales apuntan a afrontar, superar y restituir el equilibrio amenazado o perdido); y la restitución (mejor o peor lograda) de un cierto estado ideal o de normalidad.

Siguiendo a Ricoeur (1978) hemos sugerido que la trama de un relato parecería enraizarse en una precomprensión del mundo de la acción que sería, ya de por sí, esencialmente narrativa. Hemos dicho que lo que se expresa en los relatos muy bien podría ser la contracara de nuestras competencias para interpretar y ordenar nuestras conductas a partir de planes de acción (Duero, 2017). Es decir, a nuestro modo de ver, y desde otra perspectiva, Burkert propone una variante de lo que dice Ricoeur $(1978,2004)$, cuando afirma que a los elementos de cualquier relato subyace una teoría de la acción; que el cuento condensa de un modo eficaz, instrucciones sobre cómo actuar y enseñanzas sobre cómo interpretar lo acontecido. Para ello articula actos sucedidos en distintos momentos y lugares referenciando una red de motivos y razones que hace comprensibles los comportamientos de los agentes implicados.

Según creemos, resulta factible suponer que la estructura originaria del protocuento, que la organización a partir de una secuencia primitiva de motifemas, que aquello mismo que Ricoeur (1978) identifica como una forma de esquematizar e interpretar los actos humanos, pudiera resultar expresión de un modo de funcionamiento más o menos elemental pero a la vez estructural, de nuestro psiquismo, necesario para ordenar casi cualquier diacronía y casi cualquier cadena de eventos en la que participan agentes intencionados, como son los seres humanos.

Reconocemos que una hipótesis como ésta requiere de mayor sistematización y que también exige recabar material empírico que la justifique y fundamente. Así y todo creemos que la propuesta que acabamos de revisar podría aportarnos una comprensión más profunda de la cognición humana, que atienda y reconozca sus diferentes aristas, asî como a sus múltiples y heterogéneos modos de expresión. 


\section{Referencias}

Adler, J. M., Chin, E. D., Kolisetty, A. P., \& Oltmanns, T. F. (2012). The distinguishing characteristics of narrative identity in adults with features of borderline personality disorder: An empirical investigation. Journal of Personality Disorders, 26, 498-512.

Adler, J. M. \& McAdams, D. P. (2007). The narrative reconstruction of psychotherapy. Narrative Inquiry, 17, 179-202.

Adler, J. M., Wagner, J. W., \& McAdams, D. P. (2007). Personality and the coherence of psychotherapy narratives. Journal of Research in Personality, 41(6), 1179-1198.

Bamberg, M. (2012). Narrative Analysis. En H. Cooper (Ed.), APA Handbook of research methods in psychology (3 volumes), Washington, DC: APA Press.

Baumeister, R. F. \& Newman, L. S. (1994). How stories make sense of personal experience: motives that shape autobiographical narratives. Personality and Social Psychology Bulletin, 20(6), 676-690.

Barthes, R. (1991). Introducción al análisis estructural del relato. En E. Verón (Ed.), El análisis estructural los relatos (pp. 65-101). Buenos Aires: Centro de Editores de América Latina.

Barthes, R. (2005). La preparación de la novela. Buenos Aires: Siglo XXI Editores.

Bruner, J. (1987). Life as Narrative. Social Research, 54(1), 11-32.

Bruner, J. (1991a). The Narrative Construction of Reality. Critical Inquiry, 18(1), 1-21.

Bruner, J. (1991b). Actos de significado. Más allá de la revolución cognitiva. Madrid: Alianza

Bruner, J. (2002). La fábrica de historias. Fondo de Cultura Económica.

Burke, K. (1945). A Grammar of Motives. New York: Prentice Hall. Burkert, W. (2009). La creación de lo sagrado. Barcelona: Acantilado.

Campbell, J. (1959). El héroe de las mil caras. Buenos Aires: Fondo de Cultura Económica.

Capella, C. (2017). Disequilibrium and Loss of Narrative Coherence in Identity Construction: A Piagetian Perspective on Trauma in Adolescent Victims of Sexual Abuse. Journal of Constructivist Psychology, 30(4), 323-338.

Danto, A. C. (1989). Historia y narración. Ensayos de filosofía analítica de la historia. Barcelona: Paidós.

Dawkins, R. (1991). El gen egoísta. Buenos Aires: Salvat.

De Vega, M. (1998). La psicología cognitiva: ensayo sobre un paradigma en transformación. Anuario de Psicologia, 29(2), 21-44.

Dimaggio, G. \& Semerari, A. (2001). Psychopathological narrative forms. Journal of Constructivist Psychology, 14(1), 1-23.

Di Paolo, E. A. (2005). Autopoiesis, adaptivity, teleology, agency. Phenomenology and the Cognitive Sciences, 4, 97-125.

Di Paolo, E. A. (2009). Extended life. Topoi, 28, 9-21.

Di Paolo, E. A. (2010). Robotics inspired in the organism. Intellectica, 53-54, 129-162.

Di Paolo, E. A., Rohde, M., \& De Jaegher, H. (2010). Horizons for the enactive mind: values, social interaction, and play. In J. Stewart, O. Gapenne, \& E. Di Paolo (Eds.), Enaction: towards a new paradigm for cognitive science (pp. 33-87). Cambridge, MA: MIT Press.
Duero, D. G. (2011). Procesos psicológicos y mundos mentales. Córdoba: Editorial Alejandría.

Duero, D. (2017). ¿Por qué la narrativa importa a la psicología? Themata, 55, 131-156

Duero, D. \& Limón Arce, G. (2007). Relato autobiográfico e identidad personal: Un modelo de análisis narrativo. ABIR Revista Antropológica Iberoamericana, 2(2), 232-275.

Duero, D. \& Osorio, F. J. (2018). Phenomenological-narrative contributions to understand the narrative strategies that shape the autobiographical account throughout different moments of the therapeutic process. Research in Psychotherapy: Psychopathology, Process and Outcome, 21(2). doi: https://doi.org/10.4081/ ripppo.2018.309

Eco, H. (2013). Kant y el ornitorrinco. Buenos Aires: Editorial Sudamericana.

Eibl-Eibesfeldt, I. (1991). Biología del Comportamiento Humano. Madrid: Alianza.

Gallagher, S. (2000). Philosophical conception of the self: implications for cognitive science. Trends in Cognitive Sciences, $4(1), 14-21$

Greimas, A. J. (1966). Semántica Estructural. Madrid: Gredos.

Herman, D. (2002). Story Logic: Problems and Possibilities of Narrative. Lincoln, U.S.A.: University of Nebraska Press.

Herman, D. (2003). Stories as a tool for thinking. In D. Herman (Ed.), CSLI lecture notes. Narrative theory and the cognitive sciences (pp. 163-192). Chicago: Center for the Study of Language and Information.

Hermans, H. J. (2006). The self as a theater of voices: Disorganization and reorganization of a position repertoire. Journal of Constructivist Psychology, 19(2), 147-169.

Lavov, W. \& Waletsky, J. (1967). Narrative Analysis: oral version of personal experience. Journal of Narrative and Life History, 7(1-4), 3-38.

Lévi-Strauss, C. (1991). La estructura y la forma. En E. Verón (Ed.), El análisis estructural (pp. 35-54). Buenos Aires: Centro de Editores de América Latina.

Linde, Ch. (1993). Life Stories. The creation of coherence. New York: Oxford University Press.

Mc Adams, D. P. (1995). What do we know when we know a person? Journal of Personality, 63, 365-396.

Mc Adams, D. P., Hoffman, B. J., Mansfield, E. D., \& Dray, R. (1996). Themes of agency and communion in significant autobiographical scenes. Journal of Personality, 64, 339-377.

Mc Adams, D. P., Anynidoho, N. A., Brown, C., Huang, Y. T., Kaplan, B., \& Machado, M. A. (2004). Traits and Stories: Link Between Dispositional And Narrative Features of Personality. Journal of Personality, 72(4), 762-784.

Menary, R. (2006). Radical Enactivism: Focus on the Philosophy of Daniel D. Hutto. Philadelphia, U.S.A.: John Benjamins.

Menary, R. (2008). Embodied Narratives. Journal of Consciousness Studies, 15(6), 63-84.

Mélétinski, E. (1971). El estudio estructural y tipología del cuento. Madrid: Editorial Fundamentos.

Palmer, A. (2004). Fictional Minds. Lincoln, U.S.A.: University of Nebraska Press. 
Palmer, A. (2010). Social Minds in the Novel. Columbus: Ohio State University Press.

Propp, V. (1971). Morfología del cuento. Madrid: Editorial Fundamentos.

Ricoeur, P. (1978). Historia y Narratividad. Barcelona: Paidós.

Ricoeur, P. (2004). Tiempo y relato. Buenos Aires: Siglo XXI Editores.

Salvatore, G., Conti, C., Fiore, D., Carcione, A., Dimaggio, G., \& Semerari, A. (2006). Disorganized narratives: problems in treatment and therapist intervention hierarchy. Journal of Constructivist Psychology, 19, 191-207.

Todorov, T. (1975). The Fantastic: A Structural Approach to a Literary Genre. Ithaca, U.S.A.: Cornell University Press.

Todorov, T. (1991). Los géneros del discurso. Caracas: Monte Avila Editores.
Tulving, E. (1983). Elements of Episodic Memory. London: Oxford Clarendon Press.

Selde, R., Widdowson, P., \& Brooker, P. (2004). La teoría literaria contemporánea. Barcelona: Airel.

Van Dijk, T. A. (1998). Texto y Contexto. Madrid: Editorial Cátedra. White, H. (1973). Metahistoria. La imaginación histórica en la Europa del siglo XIX. México: FCE.

White, H. (1978). El texto histórico como artefacto literario. Barcelona: Paidós.

White, H. (1987). El contenido de la forma. Buenos Aires: Paidós.

Zipes, J. (2014). El irresistible cuento de hadas. Buenos Aires: Fondo de Cultura Económica. 


\section{Notas al final}

1 Como insinuara Borges en su relato Tlön, Uqbar, Orbis Tertius, la morfología oracional podría ya estar sugiriendo un tipo de ontología, un modo de concebir la realidad.

2 Entre otras cosas, las acciones implican fines. Las acciones, además, remiten a motivos que explican por qué alguien hace o ha hecho algo. Las acciones tienen también agentes, que hacen y pueden hacer cosas que se consideran como obra suya, etc.

3 Con posterioridad a Propp, diferentes narratólogos han propuesto alternativas para el análisis formal y estructural de los relatos. Greimas (1966), por ejemplo, ha desarrollado una versión renovada de la teoría proppeana contribuyendo con aportes sustanciales a la comprensión de la organización de los relatos. Aplicando el análisis semántico y atendiendo a la estructura de la frase, Greimas intentó identificar un sistema universal de oposiciones en base al cual reconocer y clasificar las acciones y tipo de funciones que cumplen los personajes. Para ello, distinguió tres modos actanciales (sujeto-objeto; remitente-destinatario; colaborador-oponente) y junto con ello, tres esquemas básicos para ordenar sus acciones (deseo, búsqueda o propósito; comunicación; ayuda u obstaculización). En base a esto postuló una gramática universal que explicaría elementos compartidos por casi todos los relatos. Excedería, por supuesto, a los objetivos de este modesto ensayo, pasar revista a ésta y las demás tradiciones que evolucionaron a partir de la propuesta formalista de Propp. Sin embargo, para el lector no especializado pero curioso, nos permitimos recomendar el trabajo introductorio de Selden, Widdowson y Brooker (2004).

4 Lo anterior no quita mérito, por cierto, al descubrimiento de Propp. Si bien superadores, los análisis estructurales de los numerosos mitos que llevara a cabo Lévi-Strauss tiene mucho en común con la propuesta formalista.

5 Desde otra perspectiva teórica, el mitólogo y psicoanalista Joseph Campbell (1959) ha hecho notar el sorprendente nivel de uniformidad que es posible reconocer, en el plano formal y a nivel de rasgos y funciones, en el modo que aparecen caracterizados los protagonistas así como en la composición de los mitos y relatos de muy diversas culturas y tradiciones. Para Campbell, los mitos, las leyendas y los relatos tradicionales serían expresión de elementos arquetípicos de la mente humana, coincidentes con lo que Jung llamara inconsciente colectivo y que provienen de un tipo de experiencia esencialmente profunda de nuestro psiquismo. 